\title{
Padrões de eficiência no comércio: definições e implicações normativas
}

Marcilene Martins

Professora Adjunta do

Departamento de Economia da UFRGS

\section{Palauras-chave \\ comércio internacional, padrões de especialização, eficiência econômica.}

Classificação JEL B50, F10, O33.

Key words

international trade, patterns of specialization, economic efficiency.

JEL Classification B50, F10, O33.

\section{Resumo}

O presente artigo discute a relação entre padrões de eficiência no comércio e especialização comercial. Partimos da hipótese de que a perspectiva de se qualificar a especialização comercial remete à necessidade de alguma noção prévia de eficiência econômica. $\mathrm{O}$ argumento central é o de que tal especificação é condição necessária ao propósito de avaliar as implicações alocativas e técnico-produtivas dinâmicas associadas a um dado qualquer padrão de especialização, inclusive no que diz respeito à possibilidade de trade-offs entre os distintos critérios de eficiência no comércio.

\section{Abstract}

This paper discusses the relationship between efficiency standards and specialization in trade. The assumption is that in order to define trade specialization, it is necessary to have a prior idea of economic efficiency. The main argument is that this background knowledge is a necessary condition in order to appreciate the allocation and dynamic technical-productive implications associated with any given specialization standard, including with regards to the possibilities of trade-offs between different criteria of efficiency in trade. 


\section{Introdução}

Quando fazemos referência ao padrão de especialização comercial de um país, pensamos na composição setorial do seu comércio exterior vis-à-vis a estrutura setorial do comércio mundial. E, quando indagamos se um padrão de especialização é de boa ou má qualidade, tendemos a compará-lo a determinado padrão de comércio internacional, avaliado como desejável segundo algum critério previamente definido. Importa também frisar que a adjetivação de um padrão de comércio como bom ou ruim, dinâmico ou inerte, traz embutida uma opção teórico-metodológica por um dado critério definido de eficiência econômica. Ocorre que nem sempre essa opção conceitual adotada é devidamente explicitada, o que acaba por induzir à falsa idéia de que existiria algo como um critério universal de eficiência, contribuindo também para obscurecer a possibilidade de uma análise efetiva das prescrições e implicações normativas que submergem a cada dado padrão de especialização.

As considerações acima sintetizam o eixo de interpretação deste artigo, cujo argumento central é o de que a perspectiva de se qualificar o padrão de especialização comercial remete à necessidade de alguma noção prévia de eficiência econômica, sendo tal especificação imprescindível ao ob- jetivo de se avaliar as implicações alocativas e técnico-produtivas dinâmicas associadas a um dado qualquer padrão de especialização comercial.

Além desta introdução, o artigo compõe-se de mais quatro seções. A seção 1 discute três noções alternativas de eficiência no comércio, demarcando suas diferenças conceituais e de caráter normativo. A seção 2 complementa essa discussão, atentando para algumas dificuldades relacionadas à operacionalização de tais conceitos de eficiência. A seção 3 caracteriza os padrões de especialização comercial definidos em correspondência aos distintos conceitos de eficiência, enfocando a questão da possibilidade de trade-offs entre eles e as implicações daí decorrentes. A seção 4 apresenta as considerações finais do artigo.

\section{1_Critérios alternativos à definição de eficiência no comércio}

Ao buscarmos por um embasamento teórico que permita uma discussão conceitual e com base nisso uma análise das implicações normativas associadas a um dado padrão de especialização comercial, deparamo-nos com a necessidade de alguma noção prévia de "progressiveness", no sentido de eficiência no comércio. A lite- 


\footnotetext{
. . . . . . . .

1 As hipóteses básicas dos modelos Ricardianos podem ser resumidas nos seguintes termos: o fator de produção, trabalho, é perfeitamente móvel no interior de um país, e imóvel externamente; existem distintas tecnologias no interior de um mesmo país de modo que a possibilidade de diferenças intersetoriais na produtividade do trabalho fica definida em função da existência de diferentes tecnologias; a produção está sujeita à ocorrência de rendimentos constantes de escala. Já os modelos Neoclássicos (Heckscher-Ohlin) distinguem-se dos Ricardianos ao suporem a existência de dois fatores de produção, capital e trabalho, cuja dotação relativa difere de país para país; que os países empregam uma mesma dada tecnologia; e que os padrões de preferência dos consumidores situados em diferentes países sejam idênticos (Gonçalves et al., 1998, p. 14-24).
}

ratura econômica oferece três possibilidades de onde apoiar tal definição: eficiência Ricardiana (Ricardian efficiency), eficiência em Crescimento (Growth efficiency) e eficiência Schumpeteriana (Schumpeterian efficiency) (Dosi, Tyson e Zysman, 1989; Dosi, Pavitt e Soete, 1990).

A eficiência Ricardiana inscreve-se no campo da teoria ortodoxa; remete, pois, às abordagens Clássica (Modelo Ricardiano) e Neoclássica (Modelo de Heckscher-Ohlin) do comércio internacional, que têm como ponto de partida o conceito de vantagem comparativa de custos. Tal conceito nos diz que um país possui vantagem comparativa na produção de um bem se o custo de oportunidade da produção desse bem em termos de outros é mais baixo do que o obtido em outros países.

Partindo desse conceito, a eficiência $\mathrm{R} i$ cardiana baseia-se na idéia-chave de que os recursos produtivos estarão sendo empregados com a máxima eficiência (alocativa), se distribuídos em consonância à estrutura intersetorial de vantagens/desvantagens comparativas de custos do país. A teoria prescreve que cada país deve se especializar em produzir bens nos quais apresente vantagem comparativa de custos. Tal condição ocorre quando o custo de oportunidade de produzir um bem em termos de outros bens é mais baixo que em outros países, donde se pode concluir que são as diferenças internacionais na produtividade do trabalho que definem a condição de vantagem/desvantagem comparativa de custos e, por conseguinte, os padrões de especialização produtiva e comercial do país.

Lembramos, no parágrafo anterior, que as teorias Ricardiana e Neoclássica do comércio internacional têm como ponto de partida comum o conceito de vantagem comparativa de custos. Ressalte-se agora que as hipóteses formuladas por uma e outra teoria, sobretudo no que diz respeito à tecnologia, são bastante distintas. ${ }^{1}$ Daí observar-se que essas teorias tomam rumos diferentes quando se trata de descrever o mecanismo básico de operação do conceito de vantagens comparativas conquanto determinante da especialização no comércio.

A teoria Ricardiana explica o comércio entre países em termos estritamente das diferenças internacionais na produtividade do trabalho, do que resulta a condição de vantagem ou desvantagem comparativa de custos de um dado país na produção de um bem qualquer. As diferenças na produtividade do trabalho entre países se explicam pela hipótese de que as tecnologias são não-uniformes, até mesmo no interior de um mesmo país.

Já a teoria Neoclássica enfoca as diferenças de recursos entre países, relacio- 
nando-as à abundância relativa dos fatores domésticos de produção e à intensidade relativa com a qual diferentes fatores de produção são usados na produção de bens distintos. A proposição central é de que os países tendem a se especializar na produção de bens cuja produção requeira maior quantidade do fator relativamente abundante em termos domésticos.

Ambas as teorias concluem pela existência de diferentes custos de oportunidade em cada país, mas, enquanto a teoria Ricardiana explica essas diferenças como decorrência da existência de diferentes tecnologias, para a teoria Neoclássica o que as explicam são as diferentes dotações de fatores de produção.

Demarcadas as diferenças de fundo entre as teorias Ricardiana e Neoclássica, cumpre agora esclarecer que, quando falamos da eficiência Ricardiana, é dos modelos de comércio desenvolvidos na tradição do pensamento Neoclássico que estamos falando. Tais modelos se baseiam na hipótese de que os mercados operam sob concorrência perfeita. Supõem, portanto, retornos constantes de escala, pleno emprego e livre mobilidade dos fatores de produção e funções de produção e de demanda "bem comportadas" (tecnologia uniforme e preferências dos consumidores estáveis) e idênticas entre países. Satisfeitas essas condi- ções, supõe-se a ocorrência de ajustamentos (via preços relativos) suficientes para garantir ex hypothesi o equilíbrio dos mercados de bens e fatores (Dosi e Soete, 1988, p. 403). Essas hipóteses desembocam na assertiva de que a especialização comercial guiada pela eficienncia Ricardiana constitui uma condição necessária e suficiente para o país obter ganhos no comércio, independentemente da magnitude absoluta dos seus custos de produção. Dito de outro modo,

De acordo com a teoria da vantagem comparativa, mesmo um país com uma desvantagem absoluta de produção, no sentido de custos de produção domésticos mais elevados para todas as mercadorias comercializadas, se beneficia do comércio pela exportação daquelas mercadorias em relação as quais suas desvantagens de produção são menores (Dosi, Tyson e Zysman, 1989, p. 6).

Como resultado, em qualquer dado momento, a estrutura intersetorial de vantagens/desvantagens comparativas de custos, que é definida pela disponibilidade relativa dos fatores de produção, determina a composição e a participação do país no comércio internacional. Os agentes econômicos responderão invariável e imediatamente a essa estrutura, desde que disponham de um sistema de incentivos (preços) que funcione a contento. Guerrieri (1994) descreve esse processo nos seguintes termos: 
$\ldots \ldots \ldots \ldots$

2 Paul Krugman chega a conclusões semelhantes, ainda no início da década de 80, ao introduzir a concorrência imperfeita e as economias de escala na teoria neoclássica do comércio, dando origem à denominada "Nova Teoria do Comércio Internacional". Cf. Krugman (1979 e 1980). Ver também Krugman e Obstfeld (2001, cap. 6).

3 Com destaque para a contribuição de A. P.

Thirlwall. Ver, por exemplo, Thirlwall (1979, 1980 e 1986) e também McCombie e Thirlwall (1994).
O pensamento ortodoxo vê a mudança estrutural como um suave e contínuo processo decorrente de uma correta estrutura de incentivos (preços) desfrutada por economias abertas. Nesta perspectiva, mudanças ao longo do tempo na estrutura industrial são meramente vistas como um sub-produto automático de mudanças em termos de vantagem comparativa. No curso do desenvolvimento, a vantagem comparativa é assegurada buscando-se por 'fundamentos corretos' ['getting fundamentals right'] através de fortes vínculos com o mercado internacional (Guerrieri, 1994, p. 171).

O relaxamento de algumas hipóteses do modelo neoclássico padrão, isto é, nos termos acima descritos, é suficiente para romper com a simplicidade do mecanismo de ajustamento e o automatismo dos resultados nele previstos. Assim, admitindo-se, por exemplo, a possibilidade de funções de produção variáveis (diferentes) entre países, a equalização de preços deixa de ser automática; admitindo-se a possibilidade de economias de escala e, por conseguinte, retornos crescentes de escala, há que se relativizar a hipótese de que as vantagens do comércio se distribuem de forma igualitária entre os países; admitindo-se a existência de "imperfeições" de mercado, a hipótese de modelos de equilíbrio "geral" para o comércio não mais se sustenta. Com efeito, tais condições apontam para resulta- dos que contrastam com os previstos pelo modelo neoclássico padrão. Nesse sentido, poder-se-ia concluir, por exemplo, que

em geral, os preços dos fatores não estão equilibrados, existem rendas oligopólicas, os padrões de comércio não dependem apenas das dotacõoes de fatores dos paises, os graus e formas de 'imperfeiçoes' de mercado tornam-se um determinante por si mesmos da localização da produção e do comércio (Dosi e Soete, 1988, p. 406). ${ }^{2}$

O conceito de eficiência em Crescimento, ainda que nomeado e operacionalizado por autores da vertente neo-schumpeteriana (Dosi, Pavitte Soete, 1990; Dosi, Tyson e Zysman, 1989), remete à teoria Kaldoriana. ${ }^{3}$ Recuperando alguns principais argumentos de Kaldor acerca da relação entre padrão de comércio exportador e crescimento econômico, sintetizamo-los nos seguintes pontos: i) o crescimento econômico é induzido pela demanda (demand-induced), ao invés de restringido pelos recursos (resource constrained), com a demanda externa vindo a cumprir o papel de principal fator propulsor do crescimento da taxa de produto; ii) variações das importações se explicam em função mais de variações da renda real do que dos preços; iii) a elasticidade-preço da demanda é um fator que importa no que tange à exportação de "bens tradicionais", isto é, no caso daqueles pro- 
dutos para os quais as inovações tecnológicas se mostrem de menor importância; iv) o crescimento das exportações de um país é resultado dos esforços feitos no sentido da busca de novos mercados potenciais e da capacidade em adaptar sua estrutura produtiva ao perfil da demanda internacional. Depende, assim, da elasticidade-renda da demanda internacional por seus produtos, a qual será tanto mais alta quanto maiores forem as capacidades inovativa e adaptativa dos exportadores; v) os países desenvolvidos apresentam elevadas elasticidadesrenda das exportações e baixas elasticidades- renda das importações, o que reflete sua liderança no desenvolvimento de novos produtos (Kaldor, 1981, p. 339-340).

A noção de eficiência em Crescimento apóia-se inteiramente nessa visão Kaldoriana do comércio, da qual incorpora a hipótese de uma relação positiva entre a magnitude da elasticidade-renda da demanda internacional, a capacidade de expansão das exportações e a taxa prospectiva de crescimento econômico. A variável-chave que define tal noção de eficiência no comércio é a elasticidade-renda das mercadorias correspondentes a um dado padrão de especialização no comércio.

A eficiência em Crescimento no comércio prescreve que as exportações de um país tenderão a crescer tanto mais rápida e firmemente quanto mais elevados os seus coeficientes de elasticidade-renda, e que o padrão de especialização no comércio será tão mais eficiente quanto maior a participação relativa de exportações de elevada elasticidade-renda da demanda internacional. É então afirmada a hipótese de uma interação positiva entre expansão das exportações e crescimento econômico, assumindo-se que uma estrutura exportadora de caráter market-dynamic pode favorecer maiores taxas de crescimento econômico, permitindo, com isso, um deslocamento "para a frente" da restrição ao crescimento imposta pelo desequilíbrio do balanço de pagamentos; mesmo na hipótese de uma elevação do coeficiente de importações induzida pelo crescimento da renda real (Dosi, Pavitt e Soete, 1990, p. 208).

Do ponto de vista normativo, o conceito de eficiência em Crescimento converge para a preocupação em avaliar como o potencial de crescimento de longo prazo pode ser afetado pela composição do produto e do comércio nacionais. A resposta a essa questão remete aos elementos considerados nos dois parágrafos precedentes, podendo ser sistematizada nos seguintes termos: tudo o mais constante, quanto maior e mais veloz a taxa de crescimento da demanda internacional pelos produtos de um país em resposta ao crescimento da renda 
mundial, maior a perspectiva de se obterem elevadas taxas de crescimento econômico. Considerando que os produtos/setores diferem entre si no tocante à elasticidaderenda, um padrão de especialização eficiente será aquele que se faça basear na exportação de produtos market-dynamics ou de alta elasticidade-renda (de longo prazo) no comércio mundial. Em perspectiva dinâmica, uma trajetória de especialização comercial convergente para o padrão de demanda internacional caracterizar-se-á por uma elevação do grau de similaridade entre as estruturas de exportação nacional e mundial.

Voltando ao esquema teórico de Kaldor, vale ressaltar a importância nele conferida ao desenvolvimento tecnológico e à habilidade inovativa dos agentes econômicos, como fatores explicativos dos diferenciais de elasticidade-renda das exportações. Nesse sentido, ao identificar na contraposição entre alta elasticidade-renda das exportações versus baixa elasticidade-renda das importações, uma situação característica aos países desenvolvidos e um reflexo de sua liderança no que concerne ao desenvolvimento de novos produtos, Kaldor explica que

o progresso tecnológico é um processo contínuo e em grande parte adquire a forma do desenvolvimento do marketing de novos produtos, os quais proporcionam uma no- va forma preferida de satisfazer alguma demanda existente. Tais novos produtos, se bem sucedidos, gradualmente substituem o produto pré-existente que serve às mesmas necessidades, e no curso desse processo de substituição, a demanda pelo novo produto cresce acima do crescimento geral da demanda resultante do crescimento econômico. Como resultado, os exportadores mais bem sucedidos estarão aptos a alcançarem maior penetração tanto nos mercados internacionais quanto nos domésticos, porque seus produtos substituirão os produtos existentes (Kaldor, 1981, p. 340).

A transcrição acima evidencia a percepção acurada de Kaldor acerca do papel central cumprido pelo progresso técnico na redefinição dos padrões de demanda e de produção nacionais. Ocorre que nem o próprio Kaldor nem os autores que sua teoria inspirara deram seqüência à análise das propriedades e características do progresso tecnológico e seus impactos dinâmicos sobre o padrão de especialização. A superação dessa lacuna pressupõe incorporar-se ao conceito de eficiência em Crescimento o caráter endógeno e dinâmico do progresso técnico. É precisamente este o ponto de partida ao conceito de eficiência Schumpeteriana, o qual pode ser considerado

[...] um desdobramento e uma sofisticação da contribuição de Kaldor, através da agregação do aporte teórico encontrado em 
Schumpeter-destacando-se, a este respeito, a introdução de uma distinção crucial entre os conceitos de 'eficiência em Crescimento' e 'eficiência Schumpeteriana' [...] que tem como raiz a endogeneização do progresso técnico feita por estes últimos (Baptista, 2000, p. 24-25).

A distinção entre as noções de eficiência em Crescimento e eficiência Schumpeteriana pode ser demarcada nos seguintes termos: a eficiencia em Crescimento se preocupa em avaliar a alocação de recursos com ênfase em seus efeitos sobre a taxa de crescimento econômico de longo prazo; a explicação para as diferenças intersetoriais de crescimento constitui o ponto de partida da eficiência Schumpeteriana, que considera o desenvolvimento tecnológico como o principal fator explicativo daquelas diferenças e o motor do crescimento econômico, enfatizando-se ainda a relação entre padrões correntes de especialização e mudança tecnológica, através dos efeitos dos primeiros sobre o ritmo e a direção desta última (Dosi, Tyson e Zysman, 1989, p. 13). ${ }^{4}$

A definição de eficiência Schumpeteriana prescreve um padrão de especialização baseado na exportação de produtos para os quais se identifique um elevado grau de oportunidade, apropriabilidade e cumulatividade tecnológica. ${ }^{5}$ A idéia de oportunidade tecnológica diz respeito às possíveis ro- tas de desenvolvimento tecnológico - em termos da possibilidade de aperfeiçoamentos e/ou ampliação do leque de "artefatos" tecnológicos e do seu escopo de aplicação - associadas a um dado paradigma tecnológico. Um grau elevado de oportunidade tecnológica significa um campo mais amplo de possibilidades de introdução de inovações. Mas tal condição não é suficiente para justificar a decisão de inovar. A disposição dos agentes econômicos privados de investirem recursos na exploração de oportunidades tecnológicas depende ainda de como avaliam o retorno econômico esperado com a inovação e a sua capacidade de apropriar-se deles. Quanto mais favoráveis forem as expectativas de "lucros monopólicos" associados à inovação, menores serão as chances de que essas sejam facilmente imitadas por terceiros, mais elevado será o grau de apropriabilidade privada dos retornos econômicos a elas associadas e maior será o estímulo à inovação.

Além da ênfase nos aspectos de oportunidade e apropriabilidade tecnológica, a noção de eficiência Schumpeteriana baseia-se na hipótese de que o padrão de mudança tecnológica não é exógeno aos padrões correntes de especialização produtiva e comercial. Estes últimos condicionarão aquele primeiro, positiva ou negativamente, a depender do que ofereçam, em ter-

\footnotetext{
4 É interessante observar que a reintrodução do tema da tecnologia como fator explicativo dos padrões de especialização no comércio significa a retomada de uma preocupação que já fora de Ricardo. A diferença está em que esse autor tinha uma visão estática da tecnologia, ao passo que os evolucionistas partem de uma concepção dinâmica. 5 Os conceitos de oportunidade, apropriabilidade e cumulatividade tecnológica perpassam grande parte da literatura neo-schumpeteriana. Entre as referências básicas, destacam-se Dosi (1982, 1984, 1987 e 1988), Nelson e Soete (1988) e Nelson e Winter (1982).
} 
$\cdots \ldots \ldots \ldots$

6 Ainda que tal interação não ocorra sempre e nem de maneira automática, há razoável evidência empírica em respaldo à hipótese de uma convergência entre os produtos/setores intensivos em tecnologia e aqueles cuja demanda internacional tende a crescer a taxas mais elevadas e a produzir maior efeito positivo sobre o crescimento econômico. A esse respeito, ver Fagerberg (1995), Amable (1996),

Dalum, Laursen e Verspagen (1996), Ross (2001). mos de externalidades positivas, oportunidades e grau de aprendizado tecnológico. Isso significa dizer que a evolução dos padrões de especialização encerra um elemento de cumulatividade ("cumulativeness"), no sentido de que o padrão corrente de alocação de recursos - ao qual corresponderá um determinado padrão de desenvolvimento tecnológico - condiciona as possibilidades futuras de especialização.

A eficiência Ricardiana é conceitualmente incompatível com as noções de effciência Kaldoriana e Schumpeteriana. Funções de produção e demanda homogêneas e "bem comportadas" intra-setores e entre países são contrárias à idéia de que as atividades econômicas diferem entre si quanto às características da tecnologia, aos atributos estéticos e funcionais (reais ou imaginários) dos produtos e ao correspondente retorno econômico, corrente e prospectivo, associado a cada produto/setor de atividade.

Já a possibilidade de complementaridade entre as noções de eficiência Kaldoriana e schumpeteriana parece evidente, desde que se aceite a hipótese de uma vinculação direta entre comércio exterior e progresso técnico. Assumindo que os produtos são não-homogêneos, ao que se associa a existência de preferências não-uniformes no consumo, não é forçosa a hipótese de uma correlação positiva entre maior grau de di- ferenciação dos produtos e maior propensão a consumir quanto mais elevado o nível de renda. Admitindo-se que a possibilidade de tornar a demanda positivamente mais elástica em relação à renda depende muito fortemente da capacidade dos produtores de diferenciarem seus produtos, e, associando-se tal capacidade à introdução de mudanças técnicas na produção, decorre logicamente a proposição de uma interação positiva entre dinamismo da demanda (interna e externa) e capacidade de inovação. ${ }^{6}$

A hipótese de uma vinculação positiva e direta entre comércio exterior e progresso técnico acha-se explícita no clássico artigo de Burenstam-Linder (1961), podendo ser também notada em Kaldor (1981). Ela estabelece uma vinculação direta entre o potencial de expansão das exportações e o grau de diferenciação de produtos, com a implicação, para a teoria do comércio, de que a contribuição das exportações para o crescimento econômico será então considerada como forte dependente da capacidade dos produtores de inovar continuamente seus produtos a fim de alcançar os mercados dos países de renda mais elevada. Essa idéia de uma complementaridade entre as noções de eficiência Kaldoriana e schumpeteriana será retomada e aprofundada por Reinert (1994). Partindo da observação de que todas as experiências bem- 
sucedidas de catching-up tiveram em comum uma estratégia de desenvolvimento nacional que combinava estímulo às atividades econômicas consideradas "superiores" com a manutenção de mercados competitivos, e assumindo a hipótese - que é também $\mathrm{Kal}$ doriana - de que algumas atividades são melhores que outras em termos da sua capacidade de induzir o crescimento e o desenvolvimento econômico, Reinert defende a tese de que o desenvolvimento econômico é um fenômeno activity-specific. Valendose dessa idéia, propõe-se então avaliar a eficiência do comércio, conquanto fator indutor do crescimento econômico, por meio de um índice de qualidade das atividades econômicas que as classifica de acordo com seu potencial de geração de riqueza e sua contribuição para o desenvolvimento econômico. Por esse índice, aquelas atividades para as quais se identifique a possibilidade de elevado (baixo) grau de oportunidade tecnológica são definidas como superiores (inferiores) (Reinert, 1994, p. 169).

Assim, em vez do critério de eficiência relativa, definida em termos de vantagem comparativa de custos, Reinert propõe distinguir entre atividades de boa ou má qualidade segundo o grau de oportunidade tecnológica que elas encerram, portanto, segundo um critério de eficiência absoluta de custos. Trata-se, pois, de uma con- cepção de eficiência diametralmente oposta à da teoria neoclássica, que considera as atividades econômicas como qualitativamente homogêneas, em termos dos seus efeitos sobre o crescimento econômico, de modo que seria indiferente ao desenvolvimento de um país que ele se especializasse em produzir computadores ou bananas.

\section{Ainda sobre os conceitos de eficiência no comércio: dificuldades operacionais}

Deseja-se aqui chamar a atenção para algumas dificuldades relacionadas à operacionalização dos conceitos de eficiência acima discutidos. O ponto em questão é que, rigorosamente falando, nenhum daqueles conceitos se mostra diretamente aplicável aos dados de comércio.

O conceito de eficiência Ricardiana baseia-se na definição de vantagem comparativa de custos. Sua aplicação implicaria a necessidade de ter em conta a composição relativa dos preços e salários em cada país considerado na transação comercial. Em termos práticos, porém, o procedimento adotado consiste em simplesmente traduzir a noção teórica de vantagem comparativa no conceito empírico de vantagem revelada pelo comércio. E, embora existam indicadores indiretos de eficiência Ricardiana (p. 
$\ldots \ldots \ldots$ A hipótese básica por trás deste raciocínio é a de que o consumo de bens de "primeira necessidade" tende a cair com o aumento da renda, e quanto mais alto o nível de renda, ao passo que o consumo de bens de "luxo" tende a fazer o movimento inverso.

8 Permanecendo constantes estas três últimas variáveis e somente nesta hipótese -, a elasticidade-renda será o fator determinante. Ver McCombie e Thirwall (1994). ex., custo unitário do trabalho, produtividade total dos fatores), permanece a questão de que o custo de oportunidade da produção local versus demanda externa não pode ser diretamente estimado, como sugere a teoria, posto que o pleno emprego dos fatores de produção nos países envolvidos na transação comercial nunca é uma hipótese que jamais se verifica.

A eficiencia em Crescimento parte da hipótese de que os coeficientes de elasticidade-renda da demanda internacional são diferentes de produto para produto, devendo a eficiência exportadora ser analisada à luz desse critério. Portanto, a rigor, dever-se-ia partir de uma classificação das exportações definida em termos de elasticidade-renda dos produtos, o que via de regra não ocorre. O que se faz, concretamente, é substituir o que deveria ser um ordenamento explícito dos produtos segundo os coeficientes de elasticidade-renda, pela hipótese intuitiva de que os produtos que apresentarem maiores taxas de crescimento no mercado mundial corresponderão aos de mais alta de elasticidade-renda. ${ }^{7}$

Uma segunda qualificação importante é que, além da elasticidade-renda da demanda internacional, condicionam a expansão das exportações: a elasticidade-preço da demanda, os preços relativos (termos de troca) e a taxa de câmbio. ${ }^{8}$ É possível, as- sim, que, mesmo um país cujo padrão de comércio seja de baixa qualidade, porquanto baseado na exportação de bens com baixo potencial de crescimento da demanda em termos de elasticidade-renda, ele consiga, a despeito disso, elevadas taxas de crescimento das exportações, em decorrência, por exemplo, de uma tendência de queda dos preços de seus produtos no mercado internacional. Logo, sem a especificação dos efeitos preço e renda na explicação da evolução das exportações, corre-se o risco de tomar por eficiência em Crescimento o que é tãosomente eficiência Ricardiana, ou seja, uma expansão das exportações explicada por uma conjuntura de preços favorável ao mercado comprador.

A aplicação do conceito de eficiência Schumpeteriana ao comércio parece ser ainda mais complexa. A dificuldade básica está em conseguir operacionalizar (mensurar) os atributos de oportunidade, cumulatividade e apropriabilidade das inovações que caracterizam o progresso técnico nos produtos/setores exportadores e importadores. Tal dificuldade decorre da complexidade inerente aos processos de geração e difusão tecnológica, os quais, por sua natureza intrinsecamente dinâmica, envolvem sempre algum grau de incerteza "substantiva" (não passível de ser eliminável por meio de cálculo probabilístico), encerram 
determinações que são de natureza path dependent (a direção imprimida ao progresso técnico não é aleatória, mas condicionada por padrões previamente selecionados) e mecanismos que são parcialmente tácitos ou específicos aos setores/produtos (as capacitações e os ativos - tangíveis e intangíveis - são específicos à firma; as estratégias competitivas e os condicionantes técnicoprodutivos respondem às especificidades do padrão de concorrência vigente no setor de atuação das firmas; as trajetórias tecnológicas respondem também às especificidades técnico-científicas colocadas por cada particular paradigma).

$\mathrm{Na}$ expectativa de algo que sirva como medida do grau de oportunidade, apropriabilidade e cumulatividade tecnológica, a alternativa tem sido a construção de indicadores de intensidade tecnológica, utilizando-se geralmente como proxy para a tecnologia uma ou mais das seguintes variáveis: taxa de desenvolvimento de novos produtos; aquisição/depósito de patentes; gasto com P\&D como proporção da produção/vendas. A hipótese, implicitamente assumida, é a de que uma maior intensidade em tecnologia pode ser tomada como sinônimo de elevada oportunidade, cumulatividade e apropriabilidade tecnológica.

Ocorre que as condicionantes da dinâmica tecnológica apenas se revelam, em sentido pleno, conquanto expressão das características essenciais das trajetórias tecnológicas. De modo que a complexidade inerente ao caráter cumulativo do conhecimento tecnológico e à natureza sector-firmspecific da apropriabilidade e oportunidade tecnológica não parece ser absolutamente resolvida por meio da utilização de indicadores de intensidade tecnológica, e isso pela razão primeira de que estes não conseguem ter em conta as diferenças relativas aos mecanismos de introdução e difusão tecnológica no interior e entre setores de atividades. $^{9}$

Uma segunda dificuldade que se apresenta à aplicação do conceito de eficiência Schumpeteriana decorre da constatação de que o fato de um país exportar produtos intensivos em tecnologia não é por si só garantia de que ele disponha de uma elevada base tecnológica, no sentido schumpeteriano, ou seja, que signifique a construção de capacidade inovativa endógena. A vinculação - quantitativa e qualitativa - entre expansão das exportações e das importações deve ser aqui considerada. ${ }^{10}$ Ocorrendo de a expansão das exportações ter como contrapartida elevados coeficientes de importação de insumos (equipamentos, componentes, etc.), e a depender das características dos ativos tecnológicos adquiridos - em termos da importância relativa do conteú- $\ldots \ldots \ldots \ldots$

Diversas análises sugerem esta interpretação. Ver, por exemplo, Pavitt (1984), Pavitt (1989), Patel e Pavitt (1994) e Guerrieri (1994).

10 Note que tal necessidade se coloca também para os modelos kaldorianos, daí o porquê de esses considerarem não apenas a elasticidaderenda das exportações, como também a das importações. 


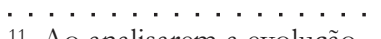

11 Ao analisarem a evolução do padrão de exportação de 20 países da Organization for Economic Co-Operation and Development (OECD), no período 1965-1992, Dalum, Laursen e Villumsen (1996) chegaram a resultados que sustentam esta hipótese. Constataram que os padrões de exportação analisados mostraram-se estáveis no longo prazo, embora tendo combinado um elemento de rigidez - caracterizado pela ausência de modificações estatisticamente significativas na composição setorial do market-share dos países - com mudanças incrementais. Concluíram, então, que ... estes resultados não deixam, portanto, dúvidas de que os padrões nacionais de especialização das exportações são muito resistentes ou rígidos. Os padrões nacionais deixam suas impressões digitais nas prováveis trajetórias do desenvolvimento futuro... (Dalum, Laursen e Villumsen, 1996, p. 21) (grifo nosso). do "público" e "protegido" da tecnologia -, bem como da forma de sua incorporação na economia - no sentido da medida do esforço imitativo/adaptativo/inovativo feito para tal incorporação -, o resultado pode ser uma elevação da restrição externa ao crescimento, no sentido Kaldoriano, ao invés de uma ampliação da base tecnológica endógena, no sentido schumpeteriano.

\section{Padrões de eficiência no comércio e a possibilidade de "trade-offs": significado e implicações normativas}

A questão essencial implicada na discussão sobre a possibilidade de trade-offs entre os diversos critérios de eficiência no comércio diz respeito a se os efeitos cumulativos associados a um dado padrão de especialização caracterizam interações "virtuosas" de aprendizado tecnológico, ou se, ao contrário, traduzem círculos "viciosos" de eficiência, no sentido de encerrarem um baixo grau de aprendizado tecnológico e, por conseguinte, baixa capacidade de aumento da qualidade da especialização no longo prazo.

Parte-se do pressuposto de que a cumulatividade, como uma característica intrínseca à evolução tecnológica, implica também supor que qualquer dado padrão corrente de alocação de recursos produtivos encerra maior ou menor grau de rigidez ("stubbornness"), no sentido de que

[...] a configuração do perfil de especialização de determinado país - on seja, o tipo e composição das atividades econômicas do país em causa e seu padrão de inserção no comércio internacional - apresenta uma inércia significativa dados os custos de entrada, de saida e irreversibilidades... (Baptista, 2000, p. 56). ${ }^{11}$

Deve ser notado que a propriedade de cumulatividade da tecnologia, que imprime à direção do desenvolvimento tecnológico um sentido de dependência à sua trajetória passada ("path-dependencie"), depõe contra a hipótese da teoria tradicional do comércio, segundo a qual o mercado por si só, necessária e automaticamente, conduziria a economia a uma situação de máxima eficiência alocativa, com o significado de que os ganhos no comércio seriam extensivos a todos os países que, sintonizados com suas vantagens comparativas naturais, comercializem entre si.

Em realidade, nada garante que a alocação de recursos induzida pela estrutura de vantagens comparativas Ricardianas será igualmente benéfica para todos os parceiros comerciais. Como observa Dosi (1987, p. 2), muito provavelmente ela não o será no caso de países que não dispõem de um eficaz regime de apropriabilidade tecnoló- 
gica e cujo padrão de especialização se caracterize pela ausência de significativas externalidades positivas e por um baixo grau de oportunidade e aprendizado tecnológico. Noutras palavras, o "ponto de partida" de cada país, no que tange aos aspectos de geração e difusão de artefatos e conhecimentos tecnológicos, é um fator que importa em termos da capacidade de apropriação de ganhos no comércio associada a um dado padrão prevalecente de especialização.

A consideração deste último aspecto remete a uma discussão importante, em termos normativos, por suas implicações relacionadas à definição de estratégias de especialização, qual seja, a possibilidade de trade-offs entre os critérios de eficiencia Ricardiana, em Crescimento e Schumpeteriana. A ocorrência de um trade-off pode ser definida como descrevendo uma situação em que a condição de máxima eficiência alocativa de curto prazo (Ricardiana) ou não signifique o máximo crescimento econômico de longo prazo ou não corresponda a um padrão de especialização que mostre um elevado grau de oportunidade e aprendizado tecnológicos que o habilite a potencializar o crescimento da economia para além do seu nível corrente. Ou seja, a existência de trade-offs caracteriza uma situação em que os critérios de eficiência no comércio não convergem entre si.
Tal discussão pode ser problematizada com base na seguinte indagação: sob que condição poder-se-ia esperar que uma alocação de recursos guiada pelos sinais de mercado e dirigida pelo objetivo do máximo retorno de curto prazo para o capital investido (eficiência Ricardiana) pudesse coincidir com a maximização do potencial de crescimento de longo prazo da economia (eficiência em Crescimento) e da taxa de mudança tecnológica (eficiência Scbumpeteriana)? Seriam duas as condições requeridas a tal convergência quanto aos critérios de eficiência no comércio: que a economia funcionasse em condição de concorrência perfeita e, nesse sentido, que qualquer dado padrão corrente de especialização correspondesse à máxima eficiência alocativa de curto prazo; que a lucratividade esperada nos setores de alta-elasticidade renda da demanda internacional e elevada oportunidade tecnológica fosse a mesma auferida dos setores correntemente explorados pela especialização no comércio. Satisfeitas essas condições, poder-se-ia supor que a especialização ótima no curto prazo mostrarse-ia igualmente ótima no longo prazo.

Sob tais hipóteses, variações nos preços de mercado desencadeariam um processo de "ajustamento Ricardiano" (Dosi, Pavitt e Soete, 1990, p. 226), à base do qual as empresas responderiam pronta- 
mente aos novos sinais do mercado, movendo-se na direção das atividades que atendessem à condição de máximo lucro/mínimo custo. Contudo, uma vez que se supõe a tecnologia constante, pode-se também supor que eventuais ganhos de eficiência surgidos desse processo seriam do tipo "once-and-for-all"."

Suponhamos, agora, uma situação em que tais condições não se verifiquem, digamos, uma economia cujos mercados de capitais e de produtos funcionem de modo "imperfeito". Na hipótese de imperfeições no mercado de capitais,

\footnotetext{
12 Neste sentido, observa-se que uma deficiência crítica da teoria ortodoxa

".... é seu tratamento da informação tecnológica como exógena ao sistema econômico, e, conseqüentemente, sua falha em oferecer qualquer entendimento de que mudanças na tecnologia (ou gostos) são mais adequadamente descritas como um processo econômico - uma falha que está estreitamente ligada à dependência do método de análise de equilíbrio de longo prazo" (Metcalfe, 1999, p. 5).

13 Compartilhando da interpretação evolucionista, entendemos não se tratar aqui de "imperfeições de mercado" - uma terminologia cujo
}

significado conceitual

inscreve-se no referencial neoclássico -, mas de assimetrias (nos mercados de capitais e de produtos) que decorrem de características inerentes ao processo de inovação e de mudança tecnológica, vale dizer, da incerteza intrínseca a esse processo. Não fosse essa incerteza, os capitalistas incluiriam nas suas projeções de rentabilidade os diferentes impactos do potencial de inovações futuras em cada projeto de investimento, decidindo então, à base desse cálculo prospectivo, o padrão de especialização corrente.
[...] empresas on futuros empreendedores podem ser capazes de levantar fundos para investimento em industrias que ofereçam altas taxas de retorno sobre um relativo curto periodo de tempo, mas incapazes de levantar fundos para investimento em indústrias que ofereçam retornos que são incertos, dadas as condições existentes do mercado mundial, e recuperáveis somente no longo prazo.

De modo análogo, a existência de imperfeições nos mercados de produtos

[...] torna impossivel reconciliar plenamente os riscos e os retornos futuros sobre o investimento corrente em indústrias e tecnologias emergentes e incertas. [...] Devido a retornos crescentes, os sinais correntes de mercado podem ser indicadores enganosos de lucratividade futura (Dosi, Tyson e Zysman 1989, p. 17).

Conclui-se disso que, na ausência de imperfeições de mercado, ${ }^{13}$ a especialização ótima no curto e no longo prazo poderiam convergir entre si, não havendo, porém, nenhuma garantia de que tal ocorra, sendo outra a situação.

A teoria evolucionista, por seu turno, concebe a tecnologia, o mercado e a relação entre ambos, numa visão diametralmente oposta à da ortodoxia econômica. Os evolucionistas interpretam os fenômenos relacionados à mudança técnica e seus 
efeitos sobre o comércio e o crescimento econômico, baseados na concepção de que a tecnologia e sua dinâmica evolutiva são endógenas ao sistema econômico; exercem importante influência na evolução das vantagens comparativas e constituem a principal fonte de criação de vantagens absolutas, portanto, da competitividade estrutural da economia; têm implicações dinâmicas sobre o ritmo e a direção do progresso técnico e o potencial de longo prazo de crescimento econômico, condicionando, portanto, as possibilidades futuras de especialização produtiva e de inserção comercial do país.

Afirma-se, assim, o caráter endógeno e dinâmico da tecnologia e o seu papel determinante na obtenção de vantagens absolutas de custos, e a visão de que o mercado, para além de sua função alocativa, constitui-se no principal mecanismo por meio do qual se processa a "seleção" das estruturas organizacionais, produtivas e tecnológicas. Admitindo-se que a economia opere em condições de mudança tecnológica, isto é, em condições não-estacionárias, o que se entende por "seleção" envolve fundamentalmente a descoberta e o aproveitamento de oportunidades geradas ou impulsionadas pela dinâmica do processo inovativo. Tal processo assume, assim, a característica de um "ajustamento dinâmi- co", por meio do qual operam as forças transformadoras da mudança tecnológica (Dosi, Pavitt e Soete, 1990, p. 226).

Ressalte-se ainda que esse processo é não-linear, ou seja, em cada dado momento, e em ritmos diferenciados, setores/ países estarão se aproximando ou se afastando da fronteira tecnológica internacional, tornando-se relativamente mais ou menos competitivos. A pressão exercida por esse "ajustamento dinâmico" sobre as vantagens absolutas de custos dos setores/países, sobrepõe-se aos efeitos estáticos do "ajustamento Ricardiano" para definir a composição do comércio e o nível de competitividade internacional de qualquer dada economia (Dosi e Soete, 1983, p. 219).

A distinção entre os processos de ajustamento "estático" (Ricardiano) e "dinâmico" (Kaldoriano e Schumpeteriano) ajuda a melhor perceber as implicações dinâmicas associadas ao surgimento de trade-offs entre as diferentes noções de eficiência no comércio. Comecemos por observar que
[...] enquanto o mecanismo das vantagens comparativas, baseado nos preços relativos e na lucratividade relativa, indubitavel- mente ainda opera e pode explicar a espe- cialização relativa, [...] qualquer medida absoluta da competitividade internacional de um país ou atividade é primariamente baseada em suas vantagens/desvantagens 
absolutas (em termos da tecnologia dos produtos e da produtividade do trabalho) (Dosi e Soete, 1983, p. 211).

Por conseguinte, a composição do comércio e o nível de competitividade internacional de uma economia qualquer determinar-se-ão em termos de eficiência Schumpeteriana, sendo, portanto,

[...] menos uma função de sua dotação nacional de fatores e vantagens comparativas naturais, e mais uma função do complexo de estratégias comerciais, industriais e tecnológicas seguidas por empresas e nações (Guerrieri, 1994, p. 199).

Assim, adicionalmente ao que já vimos discutindo, deve ser notado que, no caso de não haver uma aderência entre os critérios de eficiência alocativa estática (Ricardiana) e dinâmica (Kaldoriana e Schumpeteriana), a distância entre esses expressar-se-á fundamentalmente sob a forma de hiatos tecnológicos. Por outro lado, ressalta-se que o padrão futuro de vantagens/ desvantagens absolutas é condicionado também pelo padrão alocativo corrente.

De um ponto de vista normativo, a consideração desse condicionamento mostra-se particularmente importante na situação em que o padrão corrente de alocação de recursos tome a forma de uma especialização do tipo Ricardiana, quando se supõe que os padrões de especialização e de lucratividade setoriais respondam a decisões alocativas invariavelmente guiadas pela base de vantagens comparativas naturais do país. Supõe-se ainda que qualquer que seja o perfil de especialização resultante dessa orientação, ele terá o significado de um aproveitamento máximo dos recursos econômicos à disposição de cada agente econômico e, por extensão, significará o melhor emprego possível dos recursos da economia (máxima eficiência alocativa). E não há por que esperar que, havendo algum trade-off entre tal critério de eficiência, estática, e os critérios de eficiência dinâmica, os mecanismos endógenos de mercado por si sós conduzam à sua eliminação, já que estes (mecanismos de mercado), por hipótese, terão desde sempre operado com a máxima eficiência possível.

Ademais, analisando essa questão sob o prisma dos agentes econômicos individuais, deve ser observado que, mesmo que os empresários pudessem perceber com clareza as implicações definitivas de suas decisões presentes - por exemplo, que a decisão de não investir ou investir pouco em tecnologia fragiliza suas possibilidades de retorno futuro -, o caráter cumulativo e irrevogável das decisões anteriores pode tornar muito difícil alterar o padrão corrente de especialização em direção a um mais eficiente, do tipo Schumpeteriano. 


\section{4_Conclusões}

As concepções de eficiência no comércio acima discutidas diferem entre si quanto à definição, explícita ou não, do que seja "qualidade" da especialização. A eficiência Ricardiana, a bem dizer, nem mesmo tem qualquer preocupação diretamente relacionada à qualidade do comércio. Questões elementares, sob a perspectiva de se avaliar o padrão de comércio, tais como, o que, quanto e como se exporta, não são con- sideradas pela eficiência Ricardiana. A hipótese implicitamente assumida é a de que a satisfação da condição de eficiência Ricardiana seria também garantia de serem exportados os produtos "certos" e nas quantidades "certas". Já a definição de eficiência em Crescimento baseia-se explicitamen- te na concepção de que um padrão de comércio de boa qualidade é o que se caracteriza pela exportação de produtos com elevada elasticidade-renda no mercado in- ternacional. As questões de o que e quanto se exporta são então avaliadas com base no critério de sua aderência ou não a essa noção de eficiência no comércio. Sob a definição de eficiência Scbumpeteriana, a idéia de um perfil de especialização de boa qualidade se expressa num padrão de exportação caracterizado por produtos que signifiquem elevadas oportunidades futuras de desenvolvimento tec- nológico e de expansão das exportações no longo prazo.

As definições de eficiência no comércio aqui discutidas envolvem concepções distintas sobre o que seja "qualidade" da especialização e diferenciam-se entre si pelo modo como se relacionam com o fator tempo. Há nítida contraposição entre, de um lado, o conceito de eficiência Ricardia$n a$, cuja perspectiva de análise é estática e de curto prazo, e de outro, os conceitos de eficiência em Crescimento e Schumpeteriana, que compartilham da preocupação com as implicações dinâmicas e de longo prazo associadas a um dado padrão corrente de especialização.

Nos termos da eficiência em Crescimento, trata-se de considerar a interação entre mudanças de longo prazo na composição da demanda e da renda internacionais e capacidade de resposta ou de adaptação dos padrões nacionais de especialização comercial. A eficiência Schumpeteriana também se ocupa dessas questões, mas o faz trazendo para o centro da discussão o papel da tecnologia na configuração e evolução dos padrões de especialização e as implicações dinâmicas colocadas pela interação entre tecnologia, comércio e crescimento econômico.

De um ponto de vista normativo, a discussão em torno da possibilidade de trade-offs entre um padrão de especialização 
que atenda ao critério de eficiência Ricardiana, um que seja aderente ao critério de eficiência em Crescimento e um que corresponda ao critério de eficiência Schumpeteriana, deixou clara a importância de se conferir à análise do padrão de especialização uma perspectiva de longo prazo. Ressalta-se, nesse sentido, que os efeitos "virtuosos" ou "perversos" que decorrem a um dado padrão corrente de especialização não se restringem ao período de curto prazo, vale dizer, à esfera da distribuição intersetorial dos recursos produtivos disponíveis na economia. Tampouco tem sentido supor que o ganho ou perda de eficiência inerente ao processo de redefinição do padrão corrente de especialização seja mais bem caracterizado nos termos de um efeito "once-and-for-all", posto que os efeitos alocativos e técnico-produtivos associados a qualquer dado padrão de especialização são de caráter cumulativo e afetam o ritmo e a direção da mudança tecnológica e do potencial de crescimento econômico no longo prazo. 


\section{Referências bibliográficas}

AMABLE, B. The effects of foreign trade specialization on growth: does specialization in electronics foster growth? Maastricht: MERIT (http://meritbbs.unimaas.nl/tser. html), 1996.

BAPTISTA, M. A. C. A abordagem neo-schumpeteriana: desdobramentos normativos e implicações para a política industrial. Campinas, SP: UNICAMP, IE (Coleção

Teses), 2000.

BURENSTAM-LINDER, STAFFAN. Ensaio sobre comércio e transformação. In: SAVASINI, José A. A.; MALAN, Pedro Sampaio; BAER, Werner (Orgs.). Economia Internacional (Série ANPEC de leituras de economia). São Paulo: Saraiva, 1979. p. 65-87.

DALUM, B.; LAURSEN, K.; VERSPAGEN, B. Does specialization matter for growth? Maastricht: MERIT (http:/meritbbs.unimaas.nl/tser/ tser./html), 1996.

DALUM, B.; LAURSEN, K.; VILLUMSEN, G. The long term development of $O C D E$ export specialisation patterns: de-specialisation and "stickiness" (http:/meritbbs. unimaas.nl/tser/tser./ html), 1996.
DOSI, G. Technological paradigms and technological trajectories: a suggested interpretation of the determinants and directions of technical change. Research Policy, v. 2 n. 3, 1982.

DOSI, G. Technical change and industrial transformation. London: Macmillan Press, 1984.

DOSI, G. Some notes on patterns of production, industrial organization and international competitiveness. Paper prepared for the Meeting on "Production Reorganization and Skills". BRIE, University of California, Berkeley, September 10-12, 1987.

DOSI, G. The nature of innovative process. In: DOSI, G.; FREEMAN, C.; NELSON, R.; SILVERBERG, G.; SOETE, L. (Eds.). Technical change and economic theory. London: Pinter Publishers, 1988.

DOSI, G.; SOETE, L. Technical change and international trade. In: DOSI, G.; FREEMAN, C.; NELSON, R.; SILVERBERG, G.; SOETE, L. (Eds.). Technical change and economic theory. London: Pinter Publishers, 1988.
DOSI, G.; PAVITT, K.; SOETE, $\mathrm{L}$. The economics of technical change and international trade.

Great Britain: Harvester Weatsheaf, 1990

DOSI, G.; SOETE, L.

Technology gaps and cost-based adjustment: some explorations on the determinants of international competitiveness. Metroeconomica, v. 35, n. 3, p. 197-222, Oct. 1983.

DOSI, G.; TYSON, L.; ZYSMAN, J. Trade, Technologies, and Development: A framework for discussing Japan. In: JOHNSON, C.; TYSON, L.; ZYSMAN, J. (Eds.). Politics and productivity: how Japan's development strategy works. NewYork: Harper Business, 1989.

FAGERBERG, J. Convergence or divergence? The impact of technology on why growth rates differ. Journal of Evolutionary Economics, v. 5, p. 269-284, 1995.

GUERRIERI, P. International competitiveness, trade integration and technological interdependence. In: BRADFORD JR, C. I. (Ed.) The new paradigm of systemic competitiveness: toward more integrated policies in Latin America. OECD, Development Centre Documents, 1994.
GONCALVES, $\mathrm{R}$ et al. A nova economia internacional: uma perspectiva brasileira. Rio de Janeiro: Campus, 1998.

KALDOR, N. Equilibrium theory and growth theory. In: THIRLWALL, A. P.; TARGETTI, F. (Eds.). The Essencial Kaldor. New York: Holmes \& Meier, 1989.

KALDOR, N. The role of increasing returns, technical progress and cumulative causation in the theory of international trade and economic growth. In: THIRLWALL, A. P.; TARGETTI, F. (Eds.). The Essencial Kaldor. New York: Holmes \& Meier, 1989

KRUGMAN, P. Increasing returns, monopolistic competition, and the pattern of trade. Journal of International Economics, v. 9, p. 469-479, 1979.

KRUGMAN, P. Scale economies, product differentiation and the pattern of trade. American Economic Review, v. 70, p. 950-959, 1980.

KRUGMAN, P. R.; OBSTFELD, M. Economia internacional - teoria e prática. São Paulo: Makron Books, 2001. 
McCOMBIE, J. S. L.; THIRLWALL, A. P. Economic growth and the balance-of-payments constraint. Londres: McMillan, 1994.

METCALFE, J. S. Competitiveness and comparative advantage: (rough) notes toward an evolutionary approach to growth and foreign trade. ESRC Centre for Research on Innovation and Competition, University of Manchester, June 1999.

NELSON, R.; SOETE, L. Policy conclusions. In: DOSI, G.; FREEMAN, C.; NELSON, R.; SILVERBERG, G.; SOETE, L. (Eds.). Technical change and economic theory. London: Pinter Publishers, 1988.

NELSON, R.; WINTER, S. An evolutionary theory of economic change. Cambridge: Belknap Press of Harvard University Press, 1982.

PATEL, P.; PAVITT, K.

Uneven (and divergent) technological accumulation among advanced countries: evidence and a framework of explanation. Industrial and Corporate Change, v. 3 , n. 3 , p. $759-787,1994$.

PAVITT, K. Sectoral patterns of technical change: towards a taxonomy and a theory. Research Policy, North Holland, v. 13, n. 6,1984 .
PAVITT, K. International

patterns of technological accumulation. In: HOOD, $\mathrm{H}$. E.; VAHLNE, J. E. (Eds.). Strategies in Global Competition. London: Croom Helm, 1989.

REINERT, E. S. Catching-up from way behind. A third world perspective on first world history. In: FAGERBERG, J. The dynamics of technology, trade and growth. Edgar Elgar, 1994.

ROSS, J. Política industrial, ventajes comparativas y crecimiento. Revista de la Cepal, n. 73, p. 129-148, 2001.

THIRLWALL, A. P. The

balance-of-payments constraint as an explanation of international growth rate differences, Banca

Nazionale del Lavoro Quartely Review, v. 32, p. 45-53, 1979.

THIRLWALL, A. P.

Balance-of-payment theory and the united kingdom experience. London: Macmillan, 1980.

THIRLWALL, A. P. A general model of growth and development along Kaldorian lines. Oxford Economic Papers, v. 38, p. 199-219, 1986.

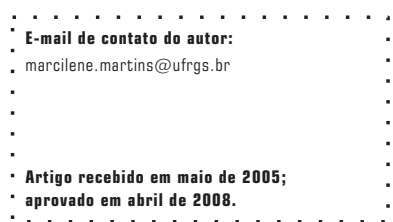

